\title{
Psicoterapia breve operacionalizada aplicada em hospital geral
}

\author{
Denise Mendes* \\ Kayoko Yamamoto** \\ Avelino Luiz, Rodrigues***
}

\section{Resumo}

O objetivo deste trabalho é apresentar um caso de Psicoterapia Breve Operacionalizada (PBO) em atendido em uma única sessão em ambiente hospitalar. São descritas as possibilidades de uso das técnicas desenvolvida pelo Prof. Ryad Simon. Os desdobramentos e as limitações encontradas no processo são expostos por meio do relato de um caso de crise por perda eminente. A análise desse caso apontou que apesar de se manter os princípios bases da PBO, a técnica não foi amplamente utilizada devido a necessidade de elaboração através do acolhimento.

Palavras chave: Psicoterapia Breve Operacionalizada (PBO); Psicologia hospitalar; Crise por perda; Psicossomática.

\section{Operationalized short-term psychotherapy in hospital: a clinical case description}

\begin{abstract}
The objective of this work is to present a case of Operationalized Short Term Therapy in a single session in a hospital setting. The possibilities of using the techniques developed by Prof. Ryad Simon. The consequences and limitations found in the process are exposed through the report of a case of crisis due to imminent loss. The analysis of this case pointed out that despite maintaining the basic principles of Operationalized Short Term Therapy, the technique was not widely used due to the need for elaboration through reception.

Key words: Operationalized Short Term Therapy; Health Psychology; Crisis for loss; Psychosomatic.
\end{abstract}

* Psicóloga, Especialista em Psicossomática e Psicoterapia Breve Operacionalizada - Membro do Laboratório de pesquisa Sujeito e Corpo, SuCor - Universidade de São Paulo, USP. E-mail: psico.denisesa@gmail.com

** Prof. Dr. em Psicologia Clínica pelo Instituto de Psicologia da Universidade de São Paulo, USP - Professora do curso de especialização em Psicoterapia Breve Operacionalizada - UNIP. E-mail: kayamato@terra.com.br

*** Prof. Dr. do Departamento de Psicologia Clínica do Instituto de Psicologia da Universidade de São Paulo, USP. Coordenador do Laboratório de Pesquisa Sujeito e Corpo, SuCor do Instituto de Psicologia USP. E-mail: avelinoluizr@usp.br 


\section{Introdução}

O hospital é marcado por situações de sofrimentos e angústias constantes. O eterno diálogo entre vida e morte, adoecimento e cura, e nas entrelinhas desses diálogos emerge o medo, insegurança, raiva e revoltas, não só para os pacientes, mas também para os familiares e em certo grau, também, para o profissional de saúde (Almeida, 2010).

Para Ismael (2005), a psicologia hospitalar aparece com o intuito de resgatar o subjetivo do sujeito em situações associadas aos adoecimentos em instituições de saúde. O papel do psicólogo é mais focal, concentrando-se no sofrimento e nas repercussões que a doença gera na hospitalização, buscando assim amenizar o sofrimento do paciente e sua família.

O trabalho do psicólogo em hospitais se diferencia dos ambientes clínicos aos quais esses profissionais estão mais habituados. O espaço físico é a primeira grande mudança, por se tratar de um ambiente tumultuado, sem muita privacidade e com frequentes interrupções por parte de outros profissionais, além dos limites institucionais, também, emergem limites no que tange quanto ao uso de estratégias e técnicas - e a PBO tem-se mostrado de grande eficácia, pois apresenta um manejo do tempo em que se dá o atendimento, visto a constante mudanças que os pacientes passam, internações em diferentes enfermarias, podendo chegar a UTI, bem como, por vezes, uma alta hospitalar abrupta e sem o devido preparo (Almeida, 2010). O atendimento hospitalar exige rapidez e brevidade, devido as urgentes demandas e a escassez do profissional psicólogo no ambiente hospitalar (Ramos; Neme \& Dameto, 2008; Oliveira \& Rodrigues, 2020).

Diante desses aspectos, nos últimos anos, vem sendo reavaliada as técnicas e métodos utilizados que proporcionem atendimentos em instituições hospitalares, que seja de duração inferior às terapias convencionais, mas que dê o suporte necessário para viabilizar um bom atendimento (Almeida, 2010).

Nessa busca por um tratamento de curta duração, uma das técnicas utilizadas é a psicoterapia breve. Essa técnica permite adaptações para diferentes contextos e permite trabalhar, em curto tempo, o sofrimento dos pacientes que necessitam do atendimento psicológico, exercendo importantes funções terapêuticas e preventivas (Ramos; Neme \& Dameto, 2008; Oliveira \& Rodrigues, 2020).

De acordo com Almeida (2010), as psicoterapias breves, usualmente, trabalham com as necessidades ime- diatas do paciente, dessa forma, possuem seus objetivos mais limitados. $\mathrm{O}$ foco passa ser o orientador da condição de psicoterapia breve. De acordo com a autora: $O$ foco on conflito focal refere-se ao conflito ou situação atual do paciente, subjacente ao qual existe o conflito nuclear exacerbado - pág 97.

Devido a multicausalidade de uma psicopatologia psicodinâmica, é improvável que uma pessoa tenha apenas um conflito, dessa forma é preciso trabalhar com situações conflitivas mais significativas dentro daquele espaço e momento.

\section{Psicoterapia Breve no hospital}

Os modelos clínicos de atendimentos psicológicos não são passíveis de utilização em instituição hospitalar (Almeida, 2010), (Oliveira \& Rodrigues, 2020). Para Ismael (2005), a realidade das instituições hospitalares é permeada de desafios para o psicólogo, e o profissional precisa trabalhar na definição de um modelo de atuação que comporte todo o setting que essas instituições exigem.

Para Almeida (2010) os quatro principais setores que o psicólogo pode desenvolver um trabalho breve, são: ambulatório, emergência, enfermaria e unidades de terapias intensivas.

Para a autora, no ambulatório é o ambiente em que mais se aproxima da prática clínica do psicólogo. O paciente vem encaminhado, usualmente, por um médico, e o setting é de algum modo tranquilo, profissional e paciente e disponibilidade de determinado tempo de sessão.

A emergência ou pronto socorro é marcado pela angústia de morte, o paciente chega a fim de restabelecer sua saúde. Nesse cenário, o psicólogo terá de realizar um atendimento ágil, marcado pela rapidez de ações e encaminhamentos para continuação do tratamento na comunidade, ou seja, a intervenção psicoterapêutica visa a uma intervenção de emergência, possibilitando o paciente a elaborar e externalizar fantasias e sentimentos em relação a doença que o levou até ao hospital.

A enfermaria é onde ocorre as internações. Neste local o profissional psicólogo irá auxiliar o paciente a elaborar o significado da internação e auxiliar os familiares a enfrentarem esse momento de angústia. Nesse ambiente o paciente perde a sua individualidade, e por muitas vezes deixa de ser ouvido em sua singularidade. Dessa forma, a psicoterapia irá atuar buscando resgatar essa singularidade perdida. As questões a serem tratadas não devem ser profundas e é importante que os atendimentos sejam iniciados e terminados, se possível em um único 
atendimento, visto a permanência variável do paciente nessas unidades. Oliveira \& Rodrigues (2020) destacam que não há a necessidade da presença do transtorno mental para o atendimento psicológico nestes espaços de prática assistencial, o sofrimento psíquico frente a própria situação de doença, a internação vivida com grande ambivalência, dos procedimentos, do prognóstico, pode-se dizer que esta situação se configura uma crise existencial, que envolve todos os níveis da vida e do viver, suas intersubjetividades.

E por último, temos as unidades de terapia intensiva, que é um espaço diferenciado do hospital, concebido como "a casa da morte" para muitos pacientes e familiares. Nessa unidade o psicólogo enfrenta desafios de magnitude considerável, a presença mais intensa e mais frequente da morte, a nudez dos pacientes, o isolamento dos pacientes de seus familiares, alterações de nível de consciência, dilemas éticos e um maior contato com os familiares (Oliveira \& Rodrigues, 2020). Assim, o trabalho do profissional psicólogo se baseia em criar condições de comunicação, de estabelecer uma escuta atenta aos focos de sofrimento, prestar esclarecimentos ao paciente de seu estado clínico, ajudá-lo a pensar, elucidar mal entendidos e assim desfazer fantasias geradoras de experiências emocionais de grande sofrimento carregadas de medo e ameaça. avaliar quadros psicopatológicos e dar suporte familiar nesse momento de angústia para todos os envolvidos.

\section{Psicoterapia Breve Operacionalizada - PBO - Breves considerações}

Simon (2011) descreve a psicoterapia breve como: 0 futuro da ajuda psicológica mais difundida (p.21).

O método proposto pelo autor é baseado na Teoria da Adaptação, em que o terapeuta identificará as situações-problema da vida do paciente e irá investigar o seu nível de adaptação com a utilização da Escala Diagnóstica Adaptativa Operacionalizada, a EDAO (Simon, 1089). Para isso, verificará as situações-problema atuais em comparações com resoluções das situações-problema antigas e observará as interações psicodinâmicas que ocorre entre elas.

Por situação problema, o autor propõe o conceito de:

Um vasto desafio que engloba a percepção de um complexo de variáveis coexistindo e interagindo simultaneamente, pressionando o sujeito a encontrar uma resposta (p.29).
Portanto, a situação-problema, não é uma situação simples que necessita ser resolvida, ela vai além, sendo uma situação significativa em que o sujeito não pode ignorá-la por longo tempo, necessita-se encontrar uma solução. Uma não solução, nesse caso, causaria uma crise na estrutura psicodinâmica do indivíduo. A fim de evitar uma crise adaptativa, o paciente terá que, em algum grau, buscar adaptações para resolver essa nova situação, mesmo que a princípio seja uma solução frustrante.

Para tal investigação, Simon (2008) criou a Escala Diagnóstica Adaptativa Operacionalizada (EDAO). A EDAO é um instrumento utilizado para determinar a eficácia adaptativa do paciente. Através do conteúdo colhido nas entrevistas, analisa-se as soluções utilizadas em situações passadas e verifica-se o nível de adequação dessas soluções. São analisados nessa escala as soluções que o sujeito tem em quatro setores distintos de sua vida, pensando sua totalidade, são eles: A-R (afetivo-relacional), $\operatorname{Pr}$ (produtividade), Or (orgânico) e S-C (sócio-cultutal). As adequações das soluções podem ser aferidas da seguinte forma:

Se a solução, de fato, resolve o problema do paciente Se essas soluções trazem satisfação, gratificação e prazer para o sujeito, e

Se essas soluções estão isentas de conflitos intrapsíquicos e/ou com o ambiente.

O resultado final dessa análise constitui a adaptação global do sujeito. Dessa forma, pode-se chegar a um dos cinco possíveis diagnósticos advindos dessa avaliação (adaptação global), são eles:

\begin{tabular}{|l|l|l|l|}
\hline Grupo 1 & Adaptação eficaz & $\begin{array}{l}\text { Muito bom } \\
\text { prognóstico }\end{array}$ & 5,0 pontos \\
\hline Grupo 2 & $\begin{array}{l}\text { Adaptação inefi- } \\
\text { caz leve }\end{array}$ & $\begin{array}{l}\text { Bom } \\
\text { prognóstico }\end{array}$ & 4,0 pontos \\
\hline Grupo 3 & Adaptação inefi- & Prognóstico & 3,0 \\
caz moderada & regular & 3,5 pontos \\
\hline Grupo 4 & Adaptação inefi- & $\begin{array}{l}\text { Prognóstico } \\
\text { reservado }\end{array}$ & $\begin{array}{l}2,0 \\
2,5 \text { pontos }\end{array}$ \\
\hline Grupo 5 & Adaptação ineficaz & Mau & 1,5 pontos \\
& grave & prognóstico & \\
\hline
\end{tabular}


Assim sendo, as situações problemas que surgem na vida do paciente devem ser avaliados de acordo com essas diretrizes para se chegar ao diagnóstico proposto pelo autor e traçar o desenvolvimento da Psicoterapia Breve Operacionalizada.

O presente trabalho foi apresentado XIV Simpósio de Psicoterapia Breve Operacionalizada a fim de suscitar o diálogo sobre a aplicação da PBO em hospitais gerais.

\section{História clínica}

\section{Sobre o atendimento}

$\mathrm{O}$ atendimento foi realizado no Hospital Universitário da Universidade de São Paulo, como parte de um estágio voluntário realizado semanalmente pelo laboratório de pesquisa Sujeito e Corpo - SuCor - do Instituto de Psicologia, sob a supervisão do Professor Avelino Luiz Rodrigues. O caso foi selecionado a partir de triagem com a equipe de enfermagem. Atendimento realizado em sessão única.

Os nomes dos sujeitos na transcrição dos foram alterados neste relato para a preservação do anonimato.

As fontes de informações clinicamente relevantes foram o prontuário médico para mensuração do sintoma e estabelecimento do plano terapêutico.

\section{Identificação do paciente}

André (nome fictício), 44 anos, casado, filho de 15 anos.

\section{Diagnóstico}

Após a conversa com o paciente, foi possível identificar que seu setor Afetivo Relacional estava pouquíssimo adequado e seu setor da Produtividade estava pouco adequado, pois devido o diagnóstico repentino da esposa, o paciente não estava conseguindo realizar qualquer atividade produtiva.

Com essa pontuação, chega-se ao diagnóstico do grupo 4: Adaptação Ineficaz Severa.

\begin{tabular}{|l|c|c|c|}
\hline \multicolumn{1}{|c|}{ Setor } & Adequado & Pouco Adequado & Pouquíssimo Adequado \\
\hline Afeito-Relacional (AR) & 3 & 2 & 1 \\
\hline Produtividade (Pr) & 2 & 1 & 0,5 \\
\hline
\end{tabular}

\section{CLASSIFICAÇÃO DIAGNÓSTICA}

\begin{tabular}{|c|c|c|}
\hline Grupo & Classificação Diagnóstica & Soma Total \\
\hline 1 & Adaptação eficaz & 5 \\
\hline 2 & Adaptação ineficaz leve & 4 \\
\hline 3 & Adaptação ineficaz moderada & 3,5 ou 3 \\
\hline 4 & Adaptação ineficaz severa & 2,5 ou 2 \\
\hline 5 & Adaptação ineficaz grave & 1,5 \\
\hline
\end{tabular}

\section{Síntese do atendimento e discussão}

André chegou ao hospital acompanhando sua esposa que há alguns dias não estava se sentindo bem, com fraqueza e dificuldade de respirar. Após a realização de alguns exames, sua esposa foi diagnosticada com câncer de mama metastático. O caso estava muito avançado, não tinha bom prognóstico e a recomendação médica foi de cuidados paliativos.

A esposa estava internada na UTI e a equipe de enfermagem solicitou atendimento psicológico, com o intuito de auxiliar no processo de elaboração desse diagnóstico. Houve algumas tentativas por parte da equipe de realizar atendimento com ela, porém ela se negava ser atendida.

Passados alguns dias, sua esposa teve uma piora, e por toda tensão existente em torno desse caso, a equipe de enfermagem, novamente, solicitou atendimento psicológico para ela. Nessa altura, ela não conseguia mais ter comunicação verbal, apenas por gesticulação. 
André estava acompanhando sua esposa, quando a terapeuta, novamente, tentou atendimento para ela, segue o breve diálogo:

Terapeuta: Boa tarde, Juliana! Sou da equipe de psicologia, gostaria de conversar brevemente com você. Podemos? Juliana gesticula com a cabeça que não, levanta a mão em sinal de afirmativo (ao qual é interpretado que ela se encontra bem) e com o dedo aponta para o marido.

Terapeuta: você gostaria que eu conversasse com seu marido?

Juliana aponta positivamente com a mão novamente.

A terapeuta questiona se André gostaria do atendimento, ele aceita prontamente, pois acredita estar precisando. A terapeuta e André se afastam do leito de Juliana e ficam próximos da porta do quarto, no qual há outros pacientes internados. A terapeuta inicia fazendo o acolhimento inicial, e preparando um melhor setting possível para acolher sua dor.

Nesse contexto hospitalar, onde já foi apontado anteriormente toda a dificuldade do setting terapêutico hospitalar, é importante uma postura de acolhimento maior por parte do terapeuta para que um vínculo de confiança de estabeleça em tão pouco tempo (Almeida, 2010).

André inicia contando como tudo está muito difícil em sua vida, que tudo aconteceu de forma inesperada e não estava sabendo lidar com a situação. Conta que há um tempo estava notando o emagrecimento da esposa, porém como ela sempre teve um perfil magro, não associou a perda de peso com algum problema de saúde. Percebeu que havia algo errado quando ela apresentou dificuldades para respirar, então levou-a ao hospital. E. desde então, viu sua vida mudar completamente.

Diz que ainda não tinha conseguido processar todas as informações recebidas, pois havia levado a esposa ao médico por dificuldade respiratória e agora tinha um câncer espalhado pelo corpo e uma eminência de morte para lidar.

Para se organizar e executar um atendimento em $\mathrm{PBO}$, a base fundamental é detectar as situações problemas por setor de adaptação. Os passos necessários para isso é a realização de entrevistas pormenorizadas, em que são realizados: anamnese contando a história e evolução da queixa; resumo da história pregressa do paciente e um interrogatório complementar a fim de investigar as áreas afetadas pelos sintomas ou dificuldades (Simon, 2005).
Diante da realidade hospitalar, com as dificuldades em construir um setting terapêutico, a qual já fizemos referência e que os movimentos dos pacientes são constantes de uma área a outra, ficam comprometidos os passos minuciosos do levantamento desses dados. Dessa forma, a terapeuta no intuito de fazer minimamente uma anamnese, pede para que André fale um pouco de sua história pregressa.

André conta que está casado há 26 anos e tem um filho de 15 anos. Disse estar com a esposa desde os 18 anos e pontua que tudo que ele tem na vida foi construído com ela. O filho disse para ele que não iria visitar a mãe no período que ela estivesse internada, e esse foi um fato que o mobilizou, mas buscou entender e respeitar sua decisão. Diz ainda que nunca foi um marido perfeito, porém ainda não sabe como seguirá sua vida sem a esposa. Relata um pouco dos planos futuros que tinha com a esposa.

Conta que a esposa está consciente de tudo que está acontecendo e pediu que ele a cremasse, no entanto, ele não consegue conversar com ela sobre nada que tenha o tom de despedida. Nesse momento André chora por longos minutos. A equipe médica entendendo a dificuldade do setting naquele momento, improvisa um espaço "reservado" com as cortinas divisórias dos leitos para uma maior privacidade no atendimento.

A terapeuta acolhe e permite a expressão de seu sofrimento. Quando está novamente apto a conversar, a terapeuta pergunta a André o que acredita que ainda precisa ser dito para a esposa.

André pontua que gostaria e dizê-la o quanto ela foi importante e fundamental em sua vida; que gostaria de pedir perdão pelos erros que cometeu e que tudo ia ser difícil por aqui sem ela; que as coisas não foram perfeitas, mas apesar de toda dificuldade a amava e iria amá-la para sempre, e que já tinha decidido cremá-la e já estava preparando tudo para isso. Paciente volta se emocionar muito nesse momento.

Considerando o setting do momento onde não havia tempo e espaço para a preparação de um plano de ação através da realização da EDAO, a terapeuta se apropriou de sua experiência clínica em Psicoterapia Breve Operacionalizada, e diante do que foi exposto no discurso do paciente, foi detectado que André estava em um momento de crise adaptativa por eminente perda. Seu setor afetado foi o Afetivo Relacional, gerando uma crise de perda de uma pessoa amada afetada no setor Orgânico. 
E o paciente não estava encontrando qualquer solução para lidar com a situação crítica (problema novo). Recebendo a classificação diagnóstica do grupo 4: Adaptação Ineficaz Severa.

Simon (2005) afirma que a função do terapeuta em situações de crises adaptativas é dar ao paciente a melhor solução possível dentro dos recursos profissionais existentes no momento. E que o melhor procedimento para lidar com uma crise adaptativa é concentrar-se na situação crítica emergente.

Diante desse conhecimento pregresso, a terapeuta identificou uma culpa sentida por André pelos erros que acredita ter cometido em seu casamento, no entanto, apesar de notar essa culpa a terapeuta percebeu que não haveria espaço, naquele momento, para uma interpretação teorizada, que de acordo com Simon (2005) é uma interpretação mais direta que produz uma segurança da veracidade da construção - onde não se dá para recuperar o que está reprimido, mas construir com o paciente uma verdade que alcança o mesmo resultado de algo reprimido que foi recapturado através de uma postura mais ativa do terapeuta que confronta o paciente com situações angustiantes e conflitivas.

Dessa forma, a terapeuta realizou um acolhimento de todo o sofrimento expresso por André e buscou oferecer a melhor solução para aquele momento. Então, diz ao paciente que percebia uma postura dele como se a esposa já não estivesse mais em vida. Apontou que André expressava tudo que gostaria de falar para esposa como se já não houvesse possibilidades de serem ditas. A terapeuta ainda pontua que no processo de morrer muitos pacientes precisam dessa conversa franca com seus familiares para poder ter uma morte menos sofrida, e então questiona a ele, o que o impende de falar tudo que precisa para a esposa.

André, emocionado, fica em silencio por alguns minutos e retoma dizendo que sabe que não tem muito tempo e que a qualquer momento sua esposa pode ter uma piora e perder a consciência. Então, pergunta à terapeuta se pode o acompanhar até o leito novamente para que ele tenha essa conversa com a esposa.

A terapeuta o acompanha distantemente e permite que o paciente tenha seu diálogo necessário com a esposa. Ao fim dele, a esposa se apresenta muito emocionada ao falar sobre a cremação.

Ao final da conversa, André foi, novamente, até a terapeuta e agradeceu, pois se conscientizou de como es- tava fugindo desse momento necessário, e que isso abriria espaço para ele conversar mais abertamente no período em que a esposa ainda estivesse com ele.

O resultado positivo nesse atendimento clínico foi possível através da criação de um espaço de acolhimento e empatia, que possibilitaram a detecção das necessidades imediatas do paciente e, por consequência, o trabalho psicoterapêutico. E também proporcionou o encaminhamento de André para atendimento psicoterapêutico, pois haviam muitas outras questões a serem elaboradas para uma adequação mais profunda na situação vivenciada.

\section{Conclusão}

Diante desse relato foi possível observar que apesar de se manter os princípios básicos da $\mathrm{PBO}$, não foi possível seguir todo o modelo proposto por Simon, por se tratar de uma situação de crise por perda no setor Afetivo Relacional. Essa é uma situação muito frequente no ambiente hospitalar, por se tratar de complicações em pessoas que têm grau de afetividade e isso exige especial acolhimento, mas os dados apresentados demonstram que a PBO, ainda que não seja aplicada em sua integralidade, evidencia sua eficácia terapêutica. Contudo, o diálogo sobre a aplicação da PBO em hospital geral foi aberto e há ainda muitas possibilidades de aplicação nos demais setores dos hospitais.

Não se pretendeu com esse relato se esgotar o diálogo do tema em foco, visto que muito ainda se tem para percorrer, visando a contribuir com a construção do conhecimento na área.

\section{Referências}

Almeida, R. A. (2010). Possibilidades de utilização da psicoterapia breve em hospital geral. Rev. SBPH, 13(1).

Ismael, S. M. C. (2005). A inserção do psicólogo no contexto hospitalar. São Paulo: Casa do Psicólogo.

Oliveira, W.L. \& Rodrigues, A.L. (2020). Prática psicológica em enfermarias hospitalares. In Rodrigues A.L. (ed) Psicologia da Saúde - Hospitalar: Abordagem Psicossomática. Barueri: Editora Manole

Oliveira, W.L. \& Rodrigues, A.L. (2020). Prática psicológica com paciente em UTI. In Rodrigues A.L. (ed) Psicologia da Saúde - Hospitalar: Abordagem Psicossomática. Barueri: Editora Manole

Ramos, F. N. N.; Neme, C. M. B \& Dameto, C. A. (2008). Relato de caso clínico: Psicoterapia breve de paciente oncológico. RedePsi.

Simon, R. (2005). Psicoterapia Breve Operacionalizada - Técnica e Teoria. São Paulo: Casa do Psicólogo.

Simon, R.; Yamamoto, K. (2008). Psicoterapia Breve Operacionalizada em situação de crise adaptativa. Mudanças - Psicologia da Saúde, 16(2), jul-dez, 144-151p.

Submetido em: 27-3-2021

Aceito em:7-10-2021 